\title{
BMJ Open Development of hypotension in patients newly diagnosed with heart failure in UK general practice: retrospective cohort and nested case-control analyses
}

\author{
Mar Martín-Pérez, ${ }^{1}$ Alexander Michel, ${ }^{2}$ Mark Ma, ${ }^{3}$ Luis Alberto García Rodríguez ${ }^{1}$
}

To cite: Martín-Pérez M, Michel A, Ma M, et al. Development of hypotension in patients newly diagnosed with heart failure in UK general practice: retrospective cohort and nested casecontrol analyses. BMJ Open 2019;9:e028750. doi:10.1136/ bmjopen-2018-028750

- Prepublication history and additional material for this paper are available online. To view these files, please visit the journal online (http://dx.doi org/10.1136/bmjopen-2018028750).

Received 21 December 2018 Revised 13 March 2019 Accepted 12 June 2019

Check for updates

(C) Author(s) (or their employer(s)) 2019. Re-use permitted under CC BY-NC. No commercial re-use. See rights and permissions. Published by BMJ.

${ }^{1}$ Centro Español de Investigación Farmacoepidemiológica (CEIFE), Madrid, Spain

${ }^{2}$ Epidemiology, Bayer Basel, Basel, Switzerland

${ }^{3}$ Bayer US LLC, Whippany, New Jersey, USA

Correspondence to

Dr Luis Alberto García

Rodríguez; lagarcia@ceife.es

\section{ABSTRACT}

Objectives Hypotension is of particular relevance for patients with heart failure (HF), since almost all HF drugs cause lowering of blood pressure (BP) and it is associated with a poor prognosis. We aimed to investigate hypotension incidence and risk factors in patients with incident $\mathrm{HF}$ in the UK.

Design Retrospective cohort study including nested casecontrol analyses.

Setting The Health Improvement Network UK primary care database.

Participants 18677 adult patients with incident HF during 2000-2005 were followed and cases of hypotension (systolic BP $\leq 90 \mathrm{~mm} \mathrm{Hg}$ ) were identified. Controls were age-matched, sex-matched and datematched to cases (1:2).

Primary and secondary outcome measures We estimated hypotension incidence in the full study population and relevant subgroups (eg, sex and age). Potential risk factors for hypotension overall and for multiple versus single hypotensive episodes were evaluated using conditional logistic regression and unconditional regression models, respectively.

Results During a mean follow-up of 3.31 years, 2565 patients $(13.7 \%)$ developed hypotension. The incidence of hypotension was 3.17 cases per 100 patient years (95\% confidence interval (CI): $3.05-$ 3.30 ), and was markedly increased in women aged $18-39$ years $(n=32 ; 17.72$ cases per 100 patientyears; 95\% Cl: 9.69-29.73). Hypotension risk factors included high healthcare utilisation (proxy measure for HF severity and general comorbidity; eg, $\geq 10$ primary care physician visits versus none, odds ratio (OR): 2.29; $95 \% \mathrm{Cl}: 1.34-3.90)$, previous hypotensive episodes (OR: 2.32; 95\% Cl: 1.84-2.92), renal failure and use of aldosterone antagonists, angiotensinconverting enzyme inhibitors and angiotensin receptor blockers. Risk factors identified for hypotension generally overlapped with those for multiple versus single hypotensive episodes.

Conclusions Hypotension occurs frequently in patients with incident HF. Our findings may help identify patients most likely to benefit from close BP monitoring. The increased incidence of hypotension in young women with $\mathrm{HF}$ requires investigation.
Strengths and limitations of this study

- We have analysed hypotension incidence and risk factors in a large real-world cohort of patients with incident heart failure in UK primary care.

- Data are from The Health Improvement Network database, which has been extensively validated for use in pharmacoepidemiology.

- Since blood pressure is not systematically tested in routine clinical practice, we cannot rule out some detection bias.

- Due to the nature of data collection during routine clinical practice, we were unable to identify reliably the subgroup of cases with orthostatic hypotension, it was unclear if diagnoses of heart failure were made according to guidelines, and data on heart failure severity and ejection fraction were not complete for all patients.

\section{INTRODUCTION}

Almost all disease-modifying treatments for heart failure (HF) reduce blood pressure (BP),${ }^{1}$ and hypotension may also be caused by severe reductions in cardiac output. ${ }^{2}$ Hypotension is therefore relevant in $\mathrm{HF}$, and can prevent patients from receiving $\mathrm{HF}$ therapies. ${ }^{3}$ In patients with $\mathrm{HF}$ and reduced ejection fraction ( $\mathrm{HFrEF}$ ), low $\mathrm{BP}$ is associated with poor prognosis. ${ }^{45}$ However, it is unclear whether the poor outcomes in patients with $\mathrm{HF}$ and hypotension are caused by the hypotension itself or by the failure to meet guideline recommendations for therapy. ${ }^{3}$

Hypotension is generally defined as systolic BP (SBP) $<90 \mathrm{~mm} \mathrm{Hg}$ and/or diastolic $\mathrm{BP}<60 \mathrm{~mm} \mathrm{Hg},{ }^{6}$ and can be asymptomatic or symptomatic. Signs and symptoms of hypotension include dizziness or lightheadedness, syncope, lack of concentration, blurred vision, nausea, fatigue, general weakness, depression, pale skin, and palpitations. ${ }^{267}$

Patients with $\mathrm{HF}$ and hypotension are not well represented in clinical trials. ${ }^{1}$ Major clinical trials of medications for chronic HFrEF 
have commonly excluded patients with low SBP and/ or symptoms of hypotension ${ }^{1}$; therefore, the incidence of hypotension in these studies may not reflect the realworld burden of disease. Population-based data on the incidence of hypotension and the role of risk factors in patients newly diagnosed with HF in routine clinical practice are sparse.

We therefore aimed to investigate the incidence of hypotension (both symptomatic and asymptomatic unless otherwise specified) and to identify risk factors for hypotension in patients newly diagnosed with HF in primary care in the UK.

\section{METHODS}

This study has a retrospective cohort design including nested case-control analyses using data from The Health Improvement Network primary care database (THIN) in the UK.

\section{Data source}

THIN is a primary care database of anonymised patient medical records in the UK, which is representative of the whole population in terms of age, sex, and geographic distribution. ${ }^{89}$ The computerised information in THIN includes demographics, details from primary care physician (PCP) visits, diagnostic and treatment information from specialist referrals and hospital admissions, results of laboratory tests, prescriptions, and a free text section. The Read classification is used to code specific diagnoses as reasons for each consultation, ${ }^{10}$ and a drug dictionary based on data from the Gemscript classification is used to record prescriptions. ${ }^{11}$ THIN has been extensively validated for use in pharmacoepidemiology. ${ }^{12}$

\section{Patient and public involvement}

This research (which was based on anonymised patient records in THIN) was done without direct patient involvement. There was no patient input in the study design, interpretation of the results or drafting of the manuscript.

\section{Study cohort and case ascertainment}

Our initial HF cohort comprised all patients in THIN aged 1-89 years between 1 January 2000 and 31 December 2005 with a first ever diagnosis of HF, excluding those with first diagnosis of HF recorded at death or postmortem. Patients with HF were identified by automated computer searches for HF Read codes, and a semi-automatic review of patient records was undertaken to obtain data on symptoms, signs and diagnostic tests. At the time of diagnosis, approximately half $(54.1 \%)$ of the patients were ambulatory and managed by a PCP only, while $27.3 \%$ were referred to a consultant and $18.6 \%$ had a related hospitalisation. ${ }^{13}$ In a random sample of the HF cohort $(\mathrm{n}=200), 84 \%$ had the diagnosis of incident HF validated by their PCP via a questionnaire. ${ }^{13}$ From this cohort, we selected individuals aged 18-89 years and excluded those with a record of cancer before the entry date (the date of the initial diagnosis of $\mathrm{HF}$ ), leaving a final study cohort of 18677 patients newly diagnosed with HF. All study cohort members were followed from their entry date until the earliest occurrence of one of the following endpoints: first recorded episode of hypotension, reaching 90 years of age, death, cancer, or the end of the study period (May 2016). We defined hypotension as SBP $\leq 90 \mathrm{~mm} \mathrm{Hg}$ recorded during follow-up, with or without symptoms. We focused on systolic hypotension, since SBP rather than diastolic BP is frequently used as the decision criterion in clinical trials ${ }^{1}$ and observational studies ${ }^{3}$ and SBP is more strongly associated with outcome than diastolic BP in observational studies. ${ }^{5}$ The date when hypotension was detected was marked as the index date.

Patients with noticeable symptoms usually associated with hypotension (listed in the Introduction), recorded within 7 days before or after the index date, were classified as symptomatic cases. We also ascertained the number of patients with multiple episodes of hypotension during follow-up (we required $\geq 7$ days between different episodes).

\section{Data collection}

For the cohort analyses, we obtained information on age and hospital/referral status at the time of HF diagnosis (start date), sex, and hypotension antecedents (ie, episodes of hypotension at any time prior to the start date using the same operational definition as for case ascertainment).

For case-control analyses, we obtained information on body mass index (BMI) and lifestyle factors (smoking status and weekly alcohol consumption) at any time before the index date, and healthcare utilisation (number of PCP visits, referrals and hospitalisations) in the year before the index date. We also extracted information on a range of comorbidities (infections in the 3 months before the index date; anaemia, depression, anxiety and sleep disorders in the year before the index date; and other comorbidities at any time before the index date). Renal function in THIN was ascertained by searching for serum creatinine measurements recorded at any time before the index date and taking the closest valid serum creatinine value. The estimated glomerular filtration rate (eGFR) was calculated using the Chronic Kidney Disease Epidemiology Collaboration equation. ${ }^{14}$ Information on the use of prescribed medications was determined between the start date and the index date and classified into four mutually exclusive time windows: current use (most recent prescription lasted until the index date or ended in the 30 days before the index date); recent use (finished between 31 and 365 days before the index date); past use (finished more than 365 days before the index date); and never use (no recorded use at any time between the start date and index date). We also analysed the effect of treatment duration (<30 days, 1-3 months, >3-12 months, and $>1$ year) on the risk of hypotension in current users of cardiovascular drugs. Furthermore, we assessed the risk of hypotension in treatment-naïve current users of 
angiotensin-converting enzyme (ACE) inhibitors (overall and according to treatment duration). We considered ACE inhibitor users to be treatment-naïve if they had $\geq 1$ year between the last prescription written before the start date and the first prescription after the start date.

\section{Statistical analyses}

Cohort analyses for hypotension

We estimated the incidence rate $(95 \%$ confidence interval (CI)) of hypotension in the cohort of patients newly diagnosed with HF overall and stratified by sex, age group, hospital/referral status at HF diagnosis, and hypotension antecedents. The risk of hypotension (hazard ratio (HR)) associated with sex and age was estimated by Cox regression modelling adjusted by age or sex as well as calendar year, PCP visits in the year before the start date, smoking, alcohol consumption, prior history of ischaemic heart disease, atrial fibrillation, peripheral venous disease, valvular disease, arterial hypertension, hyperlipidaemia, diabetes, renal failure, prior hypotension, and use of diuretics, beta-blockers, ACE inhibitors, angiotensin receptor blockers (ARBs) and calcium channel blockers (CCBs; all variables measured at the start date). Kaplan-Meier curves of patients stratified by hypotension antecedents were compared using the log-rank test.

\section{Nested case-control analysis of hypotension}

Individuals with an incident episode of hypotension (SBP $\leq 90 \mathrm{~mm} \mathrm{Hg}$ ) were cases. To select controls for each case, we performed a search on the index date for two individuals in the cohort of patients newly diagnosed with HF who were age-matched and sex-matched to the case. For 14 cases two matched controls could not be found; these 14 cases were therefore excluded from the analysis. We thus selected 5102 control patients. As this sampling method allows the control group to include future cases, there were 763 patients who were cases as well as being controls on a date before the occurrence of hypotension.

We computed odds ratios (OR) and 95\% CI for the association of hypotension with potential risk factors using conditional logistic regression models, adjusted for healthcare utilisation and cardiovascular comedication and comorbidity.

In a secondary analysis, we ran unconditional regression models comparing cases who had multiple episodes of hypotension during the follow-up with cases who had only one episode of hypotension (considered as controls for this analysis). The multivariable regression model included the following variables: sex, age, PCP visits within the year before the index date, and the time interval between the start date and the index date.

\section{RESULTS}

\section{Characteristics of patients with HF who developed} hypotension

In the HF cohort ( $\mathrm{n}=18677), 2565$ patients $(13.7 \%)$ developed $\geq 1$ episode of hypotension over a mean \pm standard
Table 1 Characteristics of patients newly diagnosed with heart failure who developed hypotension

\section{Cases with hypotension $(\mathrm{n}=\mathbf{2 5 6 5 )}$ \\ n $\%$}

\begin{tabular}{lrr}
\hline Sex & & \\
Male & 1640 & 63.9 \\
Female & 925 & 36.1
\end{tabular}

Age, years

\begin{tabular}{|c|c|c|}
\hline 18-39 & 28 & 1.1 \\
\hline $40-49$ & 53 & 2.1 \\
\hline $50-59$ & 204 & 8.0 \\
\hline $60-69$ & 496 & 19.3 \\
\hline $70-79$ & 949 & 37.0 \\
\hline$\geq 80$ & 835 & 32.6 \\
\hline Hypotension-related symptoms & 288 & 11.2 \\
\hline $\begin{array}{l}\text { Dizziness, giddiness, } \\
\text { unsteadiness, lightheadedness }\end{array}$ & 105 & 4.1 \\
\hline $\begin{array}{l}\text { Fainting, syncope, collapse, } \\
\text { blackout }\end{array}$ & 52 & 2.0 \\
\hline Nausea, vomiting, malaise & 50 & 1.9 \\
\hline $\begin{array}{l}\text { Fatigue, drowsiness, tiredness, } \\
\text { asthenia, lethargy }\end{array}$ & 41 & 1.6 \\
\hline Depression, low mood & 14 & 0.5 \\
\hline General weakness & 12 & 0.5 \\
\hline Pale skin & 5 & 0.2 \\
\hline Palpitations & 9 & 0.4 \\
\hline Prior hypotension & 219 & 8.5 \\
\hline 1 episode & 163 & 6.4 \\
\hline 2-4 episodes & 45 & 1.8 \\
\hline$\geq 5$ episodes & 11 & 0.4 \\
\hline $\begin{array}{l}\text { Recurrent hypotension episodes } \\
\text { during follow-up }\end{array}$ & 1041 & 40.6 \\
\hline 1 recurrent episode & 485 & 18.9 \\
\hline 2 recurrent episodes & 189 & 7.4 \\
\hline 3-5 recurrent episodes & 246 & 9.6 \\
\hline 6-9 recurrent episodes & 84 & 3.3 \\
\hline$\geq 10$ recurrent episodes & 37 & 1.4 \\
\hline
\end{tabular}

deviation follow-up period of 3.31 \pm 3.97 years (median: 3.12 years; interquartile range: $0.96-6.86$ ). Most of the cases were male (table 1 ), and $69.6 \%$ were aged $\geq 70$ years at the index date (mean age: $73.3 \pm 10.8$ years). Also, 1041 (40.6\%) of the cases had recurrent hypotension during follow-up

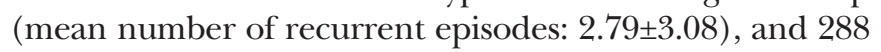
$(11.2 \%)$ had symptomatic hypotension. The most common symptoms were dizziness related (table 1).

\section{Incidence rate of hypotension}

The rates of overall and symptomatic hypotension in the HF cohort were 3.17 and 0.36 cases per 100 patient-years, 
Table 2 Incidence of hypotension in patients newly diagnosed with HF

\begin{tabular}{|c|c|c|c|c|}
\hline & $\begin{array}{l}\text { Cases with } \\
\text { hypotension }(n=2565)\end{array}$ & $\begin{array}{l}\text { Person-time } \\
\text { (years) }\end{array}$ & $\begin{array}{l}\text { Incidence of } \\
\text { hypotension per } 100 \\
\text { patient-years* }\end{array}$ & $95 \% \mathrm{Cl}$ \\
\hline Overall hypotension & 2565 & 80840 & 3.17 & 3.05 to 3.30 \\
\hline Symptomatic hypotension only & 288 & 80840 & 0.36 & 0.32 to 0.40 \\
\hline \multicolumn{5}{|c|}{ Hospital/referral status at HF diagnosis } \\
\hline Primary care & 502 & 12403 & 2.76 & 2.61 to 2.92 \\
\hline \multicolumn{5}{|l|}{ Hypotension antecedents } \\
\hline No & 2346 & 78881 & 2.97 & 2.86 to 3.10 \\
\hline$\geq 1$ episodes & 219 & 1959 & 11.18 & 9.79 to 12.76 \\
\hline
\end{tabular}

*Incidence rates are presented for overall (symptomatic and asymptomatic) hypotension unless otherwise specified.

$\mathrm{Cl}$, confidence interval; HF, heart failure.

respectively (table 2). Hypotension was recorded during the first year of follow-up in 789 cases $(30.8 \%)$, yielding a rate of 5.04 cases per 100 patients in the first year after diagnosis of HF (95\% CI: 4.70-5.40). The incidence rate of hypotension was relatively constant in all age groups in men, whereas in women the rate was highest in those aged 18-39 years (figure 1). Mean SBP within the 3 months before the start date was $117 \mathrm{~mm} \mathrm{Hg}$ and $144 \mathrm{~mm} \mathrm{Hg}$ in women aged 18-39 years and $\geq 40$ years, respectively.

We observed a higher incidence rate in patients who were HF-hospitalised at the start date compared with those who were referred to a specialist or managed only by the PCP (table 2). The incidence rate was also significantly higher in patients with versus without hypotension antecedents (table 2). The increased rate in patients with hypotension antecedents was relatively constant over the duration of follow-up and became more pronounced with increasing number of hypotension antecedents (figure 2).

\section{Risk factors for development of hypotension Cohort analysis}

Men had a significantly higher risk of developing hypotension than women (HR: $1.41 ; 95 \%$ CI: $1.29-1.54$ ), and

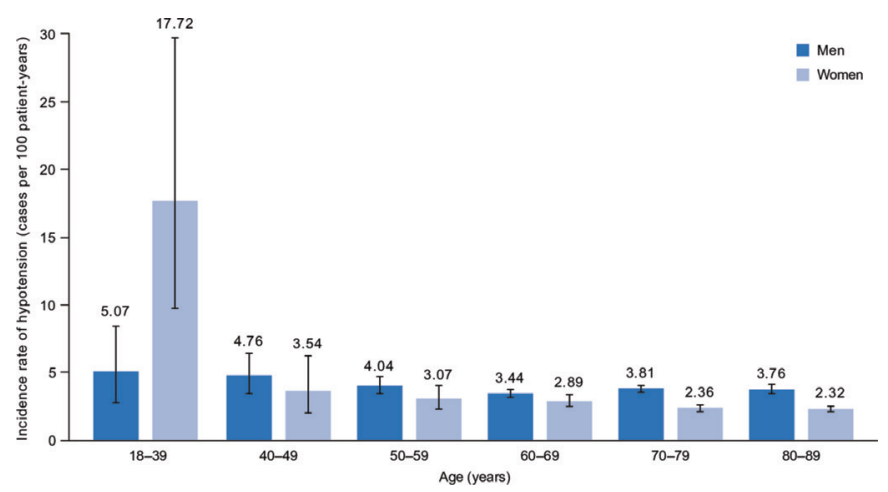

Figure 1 Incidence of hypotension in patients newly diagnosed with heart failure, stratified by age and sex. the risk of hypotension increased with decreasing age (HR (18-39 vs $\geq 80$ years]: 1.72; 95\% CI: 1.19-2.48).

\section{Nested case-control analysis}

We observed a significantly increased risk of hypotension in patients with high healthcare utilisation (table 3 ). Patients who were overweight (BMI: $25-29.99 \mathrm{~kg} / \mathrm{m}^{2}$ ) or obese (BMI: $\geq 30 \mathrm{~kg} / \mathrm{m}^{2}$ ) had a lower likelihood of hypotension than patients with normal BMI $\left(20-24.99 \mathrm{~kg} / \mathrm{m}^{2}\right)$. There were no significant associations with other lifestyle factors (online supplementary table S1).

Of the examined cardiovascular comorbidities (table 3 and online supplementary table S1), hypotension antecedents, ischaemic heart disease, valvular cardiac disease and hyperlipidaemia were associated with an increased risk of hypotension. As expected, hypertension was associated with a markedly decreased risk of hypotension. Renal failure was an independent predictor of hypotension, with the risk of hypotension increasing with decreasing eGFR. Other non-cardiovascular comorbidities including infections (respiratory and genitourinary), hypothyroidism, anaemia, liver disease, chronic obstructive pulmonary disease, depression, and dementia were associated with an increased risk of hypotension, and diabetes was associated with a decreased risk (table 3 ).

Of the evaluated cardiovascular medications (table 3 and online supplementary table S1-2), aldosterone antagonists, ACE inhibitors and ARBs were associated with the largest increases in the risk of hypotension (current versus never use). Current use of CCBs was associated with a reduced risk of hypotension. In current users of cardiovascular drugs, the period of greatest risk was generally the first month of treatment (online supplementary table S3). The effect of treatment duration was particularly marked in treatment-naïve current users of ACE inhibitors. Of the evaluated non-cardiovascular drugs (table 3 and online supplementary table S1), antidepressants and opioids were associated with an increased risk of 
A
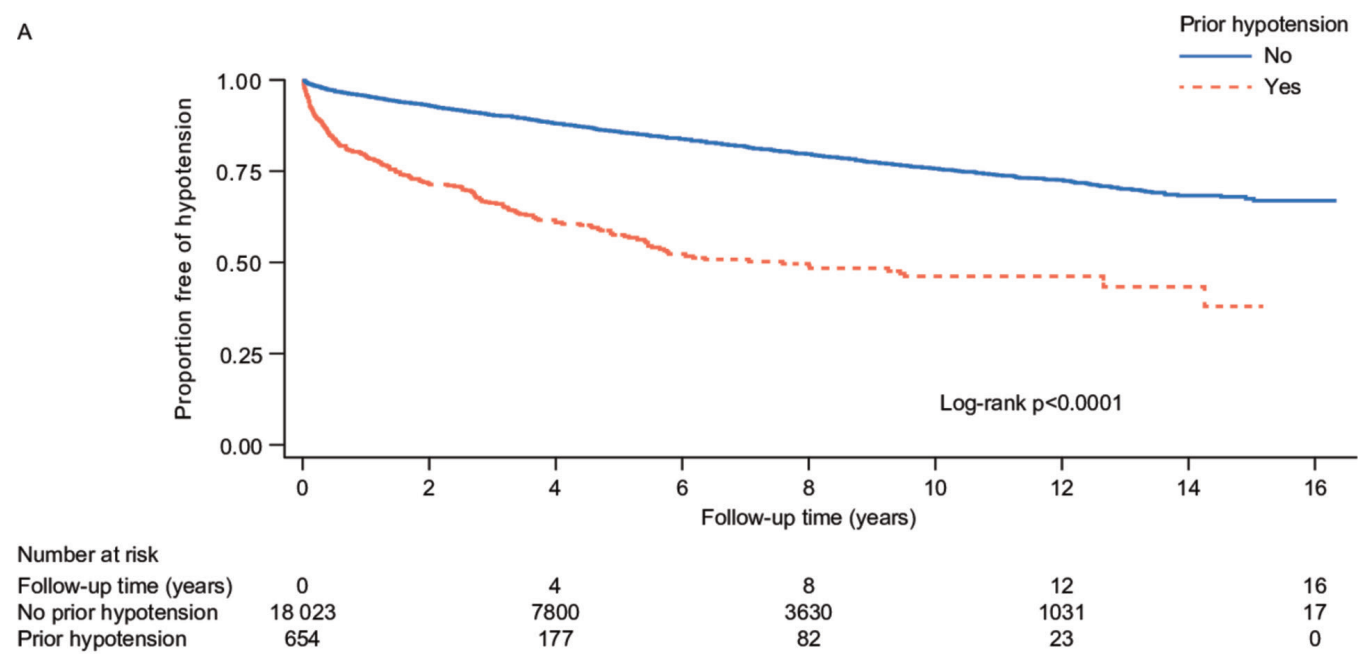

$\begin{array}{lr}8 & 12 \\ 3630 & 1031\end{array}$

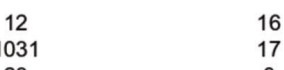
Prior hypotension

654

B
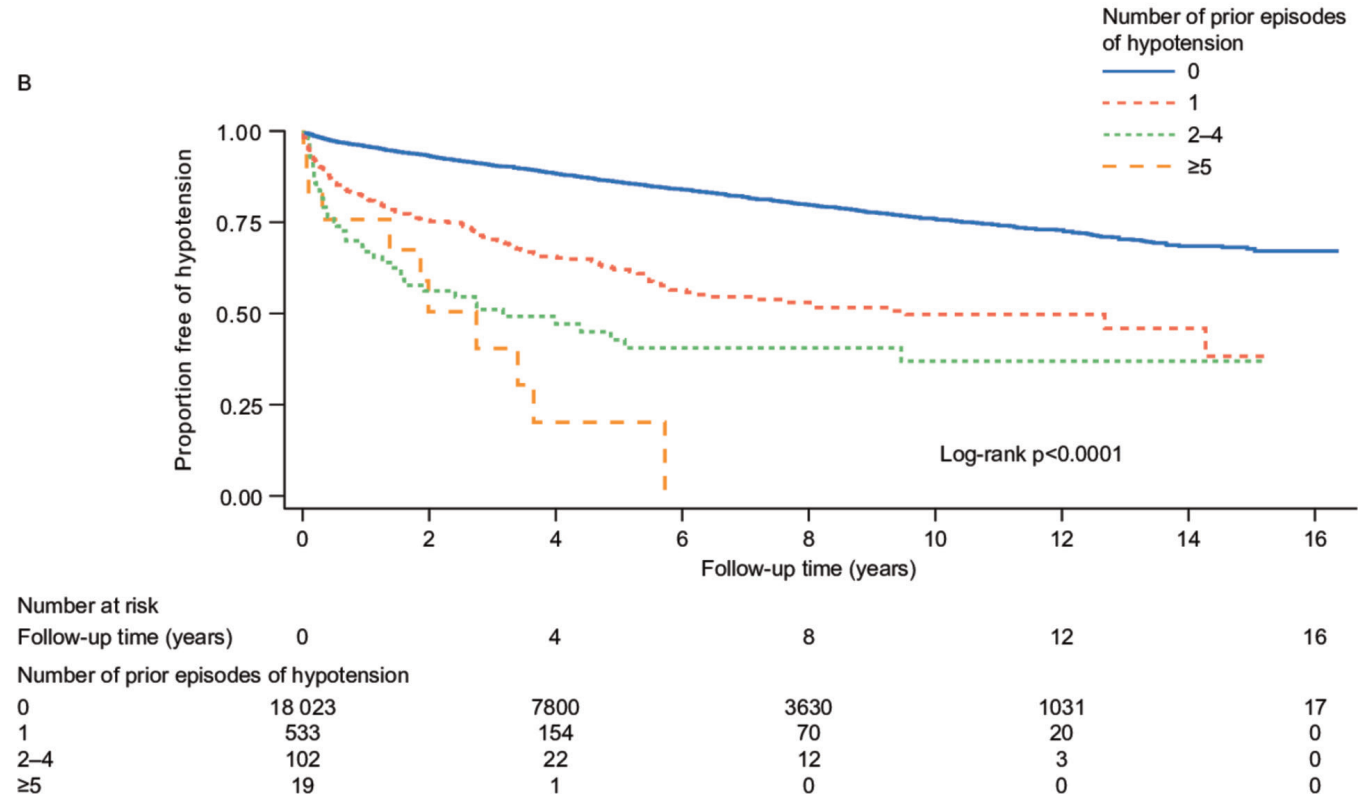

$\begin{array}{cc}12 & 16 \\ 1031 & 17 \\ 20 & 0 \\ 3 & 0 \\ 0 & 0\end{array}$

Figure 2 Kaplan-Meier estimates for development of hypotension in patients newly diagnosed with heart failure, stratified by (A) occurrence of hypotension before the heart failure diagnosis and $(B)$ number of hypotension episodes before the heart failure diagnosis.

hypotension, and antidiabetic medications were associated with a decreased risk.

\section{Secondary analysis: risk factors for multiple versus single episodes of hypotension}

Male sex, young age, and hypotension antecedents (before entering the study) were important predictors of developing multiple versus single episodes of hypotension (online supplementary table S4). Obese patients were less likely than patients with normal BMI to develop multiple episodes of hypotension. Patients with ischaemic heart disease were at increased risk and patients with hypertension, anaemia or proteinuria were at decreased risk of having multiple episodes of hypotension. Significant associations between medication use and the risk of multiple episodes of hypotension are shown in online supplementary table S4.

\section{DISCUSSION}

Our analysis of a large, validated primary care database showed that hypotension occurs frequently in patients newly diagnosed with HF in the UK, and identified several patient characteristics associated with the development of hypotension.

Much of the available data on hypotension in patients with HF stems from clinical trials. However, clinical trials of HF drugs often excluded patients with low SBP and/or symptomatic hypotension, ${ }^{1}$ those with severe comorbidities such as severe renal failure, ${ }^{1516}$ or those with late-stage HF. Consequently, lower incidences of hypotension could be expected in contemporary clinical trials compared with real-world clinical practice. ${ }^{1}$

In key successful clinical trials in chronic HFrEF, post-randomisation hypotension occurred in 0\%-20\% of patients in the control groups. The definition of 
Table 3 Factors significantly associated with the development of hypotension in patients newly diagnosed with heart failure

\begin{tabular}{llll}
$\begin{array}{l}\text { Controls } \\
(n=5102)\end{array}$ & & \multicolumn{2}{l}{$\begin{array}{l}\text { Cases with hypotension } \\
(\mathrm{n}=2551)\end{array}$} \\
\cline { 1 - 1 } & $\%$ & & $\%$
\end{tabular}

$\mathrm{OR}^{*}$

$95 \% \mathrm{Cl}$

Lifestyle factors

BMI $\left(\mathrm{kg} / \mathrm{m}^{2}\right)$

\begin{tabular}{|lrrrrll}
\hline $11-19.99$ & 221 & 4.3 & 155 & 6.1 & 1.20 & 0.94 to 1.54 \\
\hline $20-24.99$ & 1137 & 22.3 & 691 & 27.1 & \multicolumn{1}{l}{1} & \multicolumn{1}{l}{-} \\
\hline $25-29.99$ & 1701 & 33.3 & 817 & 32.0 & 0.76 & 0.66 to 0.88 \\
$\geq 30$ & 1560 & 30.6 & 670 & 26.3 & 0.64 & 0.55 to 0.74 \\
Unknown & 483 & 9.5 & 218 & 8.5 & 0.73 & 0.59 to 0.90
\end{tabular}

Healthcare utilisation

PCP visits $†$

\begin{tabular}{|c|c|c|c|c|c|c|}
\hline $0-3$ & 105 & 2.1 & 17 & 0.7 & 1 & - \\
\hline $4-9$ & 771 & 15.1 & 208 & 8.2 & 1.32 & 0.76 to 2.30 \\
\hline$\geq 10$ & 4226 & 82.8 & 2326 & 91.2 & 2.29 & 1.34 to 3.90 \\
\hline \multicolumn{7}{|l|}{ Referrals $†$} \\
\hline None & 1022 & 20.0 & 355 & 13.9 & 1 & - \\
\hline $1-3$ & 1900 & 37.2 & 873 & 34.2 & 1.20 & 1.02 to 1.41 \\
\hline$\geq 4$ & 2180 & 42.7 & 1323 & 51.9 & 1.41 & 1.20 to 1.65 \\
\hline \multicolumn{7}{|l|}{ Hospitalisations $\dagger$} \\
\hline None & 3487 & 68.3 & 1409 & 55.2 & 1 & - \\
\hline$\geq 1$ & 1615 & 31.7 & 1142 & 44.8 & 1.53 & 1.37 to 1.71 \\
\hline \multicolumn{7}{|l|}{ Cardiovascular comorbidities $\ddagger$} \\
\hline Hypotension antecedents & 160 & 3.1 & 210 & 8.2 & 2.32 & 1.84 to 2.92 \\
\hline 1 episode & 131 & 2.6 & 155 & 6.1 & 2.09 & 1.61 to 2.71 \\
\hline$\geq 2$ episodes & 29 & 0.5 & 55 & 2.1 & 3.31 & 2.06 to 5.34 \\
\hline Ischaemic heart disease & 2940 & 57.6 & 1688 & 66.2 & 1.36 & 1.22 to 1.53 \\
\hline Myocardial infarction & 1519 & 29.8 & 1009 & 39.6 & 1.35 & 1.20 to 1.52 \\
\hline Stable angina & 1671 & 32.8 & 967 & 37.9 & 1.14 & 1.01 to 1.28 \\
\hline Unstable angina & 363 & 7.1 & 269 & 10.5 & 1.25 & 1.03 to 1.52 \\
\hline Valvular cardiac disease & 612 & 12.0 & 378 & 14.8 & 1.19 & 1.03 to 1.38 \\
\hline Hyperlipidaemia & 1419 & 27.8 & 800 & 31.4 & 1.15 & 1.02 to 1.30 \\
\hline Hypertension & 3080 & 60.4 & 1255 & 49.2 & 0.59 & 0.52 to 0.66 \\
\hline
\end{tabular}

Other specific comorbidities $\ddagger$

Renal failure§

\begin{tabular}{|c|c|c|c|c|c|c|}
\hline No (eGFR $\left.>60 \mathrm{~mL} / \mathrm{min} / 1.73 \mathrm{~m}^{2}\right)$ & 1816 & 35.6 & 707 & 27.7 & 1 & - \\
\hline eGFR $45-59 \mathrm{~mL} / \mathrm{min} / 1.73 \mathrm{~m}^{2}$ & 1324 & 26.0 & 648 & 25.4 & 1.16 & 1.00 to 1.33 \\
\hline eGFR $30-44 \mathrm{~mL} / \mathrm{min} / 1.73 \mathrm{~m}^{2}$ & 1005 & 19.7 & 635 & 24.9 & 1.44 & 1.23 to 1.68 \\
\hline eGFR $<30 \mathrm{~mL} / \mathrm{min} / 1.73 \mathrm{~m}^{2}$ & 439 & 8.6 & 342 & 13.4 & 2.01 & 1.66 to 2.43 \\
\hline eGFR not recorded & 518 & 10.2 & 219 & 8.6 & 1.23 & 0.99 to 1.52 \\
\hline Diabetes & 1334 & 26.1 & 642 & 25.2 & 0.85 & 0.75 to 0.96 \\
\hline \multicolumn{7}{|l|}{ Infectionsף } \\
\hline Respiratory & 497 & 9.7 & 2962 & 11.6 & 1.31 & 1.12 to 1.52 \\
\hline Genitourinary & 114 & 2.2 & 91 & 3.6 & 1.64 & 1.21 to 2.23 \\
\hline Hypothyroidism & 508 & 10.0 & 318 & 12.5 & 1.18 & 1.00 to 1.39 \\
\hline Anaemiaๆ & 215 & 4.2 & 151 & 5.9 & 1.35 & 1.07 to 1.71 \\
\hline
\end{tabular}

Continued 
Table 3 Continued

\begin{tabular}{|c|c|c|c|c|c|c|}
\hline & \multicolumn{2}{|c|}{$\begin{array}{l}\text { Controls } \\
(n=5102)\end{array}$} & \multicolumn{2}{|c|}{$\begin{array}{l}\text { Cases with hypotension } \\
(\mathrm{n}=2551)\end{array}$} & \multirow[b]{2}{*}{$\mathrm{OR}^{*}$} & \multirow[b]{2}{*}{$95 \% \mathrm{Cl}$} \\
\hline & $\mathbf{n}$ & $\%$ & $\mathbf{n}$ & $\%$ & & \\
\hline COPD & 968 & 19.0 & 512 & 20.1 & 1.18 & 1.03 to 1.36 \\
\hline Depressionף & 214 & 4.2 & 159 & 6.2 & 1.61 & 1.28 to 2.03 \\
\hline \multicolumn{7}{|l|}{ Cardiovascular drugs ${ }^{\star *}$} \\
\hline Diuretics†† & 3741 & 73.3 & 2138 & 83.8 & 1.49 & 1.24 to 1.80 \\
\hline Aldosterone antagonists & 747 & 14.6 & 864 & 33.9 & 2.54 & 2.23 to 2.90 \\
\hline ACE inhibitors & 2906 & 57.0 & 1665 & 65.3 & 1.68 & 1.44 to 1.95 \\
\hline ARBs & 869 & 17.0 & 456 & 17.9 & 1.33 & 1.12 to 1.58 \\
\hline \multicolumn{7}{|l|}{ Other drugs ${ }^{\star \star}$} \\
\hline Antidepressants & 740 & 14.5 & 484 & 19.0 & 1.36 & 1.18 to 1.57 \\
\hline Opioids & 592 & 11.6 & 372 & 14.6 & 1.24 & 1.06 to 1.45 \\
\hline Antidiabetics & 934 & 18.3 & 432 & 16.9 & 0.79 & 0.68 to 0.91 \\
\hline
\end{tabular}

${ }^{*}$ The OR was adjusted for PCP visits, use of antihypertensive medications (thiazides and related diuretics, loop diuretics, aldosterone antagonists, ACE inhibitors, ARBs, CCBs, and beta-blockers), hypertension, renal failure, ischaemic heart disease, and valvular cardiac disease.

†Healthcare utilisation in the year before the index date was assessed.

$\ddagger$ The reference category was the absence of the corresponding comorbidity.

§Renal function was ascertained by searching for serum creatinine measurements any time before the index date and taking the closest valid serum creatinine value. The eGFR was calculated using the Chronic Kidney Disease Epidemiology Collaboration equation.

IAnaemia and depression were assessed in the year before the index date and infections in the 3 months before the index date.

${ }^{\star *}$ Current use (0-30 days before the index date) was compared with never use as the reference category.

††Other subtypes of diuretics (thiazide and loop diuretics) and subtypes of CCBs (dihydropyridines and non-dihydropyridines (verapamil and diltiazem)) are presented in online supplementary table S2.

$\mathrm{ACE}$, angiotensin-converting enzyme; ARB, angiotensin receptor blocker; BMI, body mass index; CCB, calcium channel blocker; Cl, confidence interval; COPD, chronic obstructive pulmonary disease; eGFR, estimated glomerular filtration rate; OR, odds ratio; PCP, primary care physician.

hypotension differed between the trials and BP monitoring was inconsistent. ${ }^{1}$ However, the overall frequency of hypotension observed in our study (13.7\%) lies well within this range.

There is sparse real-world evidence on the incidence of hypotension in patients with HF. In a Russian study of 199 patients with chronic HF followed for 24 months, arterial hypotension (BP $\leq 100 / 60 \mathrm{~mm} \mathrm{Hg}$ ) was identified in $6.5 \%$ of the patients based on measurements taken during medical visits, but this proportion rose to $65.8 \%$ when based on 24hour BP monitoring (with hypotension defined as daytime $\mathrm{BP} \leq 100 / 60 \mathrm{~mm} \mathrm{Hg}$ or nocturnal $\mathrm{BP} \leq 85 / 47 \mathrm{~mm} \mathrm{Hg}) .{ }^{17}$ In a US-based retrospective observational study of 104 patients with HF who began treatment with spironolactone, $7 \%$ developed hypotension (defined as SBP $<90 \mathrm{~mm} \mathrm{Hg}$ and a decrease in SBP by $>15 \%$ from pre-treatment baseline). ${ }^{18}$

Our data showed that beta-blockers, ACE inhibitors, ARBs and aldosterone antagonists - drugs with well-known effects on $\mathrm{BP}^{19}$ - are positively associated with hypotension in patients with HF. Beta-blockers are expected to lower BP owing to their vasodilatory effects, ${ }^{16}$ but were associated with only a slightly increased risk of hypotension in our study. The increased risk of hypotension associated with ACE inhibitors, ARBs or aldosterone agonists results from blockade of the renin-angiotensin-aldosterone system: ACE inhibitors reduce levels of angiotensin II and ARBs block signalling of angiotensin II via the angiotensin I receptor (thus reducing vasoconstriction and sodium chloride reabsorption), while aldosterone antagonists reduce sodium reabsorption and potassium secretion in distal tubules. ${ }^{20}$ Hypotension was one of the most common adverse events in two pivotal trials of the ACE inhibitor enalapril in $\mathrm{HF}^{21}{ }^{22}$ and ARBs are as likely as ACE inhibitors to cause hypotension. ${ }^{23}$ Both ACE inhibitors and ARBs were associated with a $<2$-fold increased risk of hypotension in our study (current versus never use), and we found a greater increase in risk associated 
with aldosterone antagonists (2.5-fold). A meta-analysis of 16 randomised controlled trials involving 31429 patients with HF also showed that addition of ARBs to conventional therapy (including ACE inhibitors) significantly increased the rate of hypotension compared with placebo (rate ratio: $1.63 ; 95 \%$ CI: 1.30 to 2.62 ) ${ }^{24}$ consistent with the association of increasing neurohormonal blockade with an increased risk of hypotension. ${ }^{120}$ However, in contrast to our findings, the meta-analysis showed only a non-significant increase in the rate of hypotension with addition of aldosterone antagonists to conventional therapy (rate ratio: $1.35 ; 95 \%$ CI: $0.78-2.41$ ). In the meta-analysis, the incidence of hypotension per 100 patient-years was 4.49 (95\% CI: 3.34-6.66), 3.66 (95\% CI: 2.07-6.12) and 2.71 (95\% CI: 2.11-3.30) in patients receiving ARBs, aldosterone antagonists and placebo, respectively. ${ }^{24}$ We found a decreased risk of hypotension associated with CCB use; this is likely to be due to confounding by indication, because CCBs are usually indicated for hypertension. Although certain HF treatments are associated with an increased risk of hypotension, the previously reported benefits of these treatments (even in patients with low SBP $)^{3}$ must also be considered; careful up-titration to target doses with adjustment of other medications and management of comorbidities may help to optimise the benefit/risk balance. ${ }^{25}$

The incidence of hypotension in younger women (aged 18-39 years) with HF was much higher than the overall incidence in our study (figure 1). To the best of our knowledge, this has not been described before. While this result should be interpreted cautiously based on the small number of women in this age group $(n=32)$, it is interesting to note that the same group also showed an elevated risk of ischaemic cerebrovascular events in a previous investigation of this HF cohort, ${ }^{26}$ and that orthostatic hypotension was identified as a risk factor for stroke in a meta-analysis of observational studies. ${ }^{27}$ This finding thus deserves further evaluation.

In patients with HF, BP decreases with advancing pump failure; hypotension can thus be a sign of advanced or severe HF. ${ }^{25}$ In our study, the severity of HF could not be measured directly, but different types of healthcare utilisation were assessed as proxy measures for HF severity and showed a clear positive association with hypotension.

We identified hypotension antecedents, ischaemic heart disease and hyperlipidaemia as risk factors for hypotension. These findings are consistent with results from the Organised Programme to Initiate Lifesaving Treatment in Hospitalised Patients with HF (OPTIMIZE-HF) registry ${ }^{5}$ and the Efficacy of Vasopressin Antagonism in HF Outcome Study with Tolvaptan (EVEREST) ${ }^{19}$ and Candesartan in HF: Assessment of Reduction in Mortality and Morbidity (CHARM) ${ }^{28}$ clinical trials, in which ischaemic aetiology, hypercholesterolaemia and discontinuation due to hypotension were more common in patients with lower SBP. We also found a reduced risk of hypotension in patients with diabetes or receiving antidiabetic medication and in patients with hypertension; again, these results are consistent with the known association between diabetes and hypertension ${ }^{29}$ and results from the EVEREST trial in patients with HF, in which diabetes and hypertension were less common in patients with lower SBP. ${ }^{19}$ Male sex and young age were associated with an increased risk of hypotension in our study; the proportion of men also increased with decreasing SBP in OPTIMIZE-HF, EVEREST and CHARM, and age decreased with decreasing SBP in EVEREST and CHARM. ${ }^{5} 1928$ Obese or overweight patients in our study were less likely to develop hypotension than patients of normal weight, consistent with the well-known association between obesity and hypertension ${ }^{30}$ and data from the general population suggesting that thinner individuals are more likely to have hypotension. ${ }^{31}$ Hypotension has been associated with cognitive impairment in several previous studies $^{32}$ and was associated with dementia in our analysis. Orthostatic hypotension is also a symptom of Parkinson disease ${ }^{33}$ but we found no significant association between Parkinson disease and hypotension in patients with HF. We observed an increased risk of hypotension in patients with recent depression. Depression is a common clinical problem among patients with $\mathrm{HF}$ and has been associated with poor HF outcomes. ${ }^{34}$ Furthermore, we found that hypotension during follow-up was related to other intervening medical events, such as anaemia. Other studies in patients with advanced HF showed that those with lower haemoglobin levels had lower blood pressure. ${ }^{35}{ }^{36}$ Several comorbidities, both cardiovascular and non-cardiovascular, have shown a statistically significant association with hypotension in patients with newly diagnosed HF; however, these associations may not reflect causal effects.

The risk factors we identified for hypotension generally overlapped with those for multiple versus single episodes of hypotension.

\section{Limitations}

Detection of hypotension depends on BP monitoring frequency, ${ }^{17}$ thus we cannot rule out some detection bias. BP is not systematically recorded in routine clinical practice; however, any misclassification would be non-differential. On the other hand, as shown by study data, healthcare utilisation within the year before the index date was greater among cases than controls, which could increase the likelihood of having BP measured and therefore the possibility of having a hypotension episode detected. Nonetheless, the impact of this on hypotension ascertainment, if any, might be small, as the mean number of recorded BP measures within the year prior to the index date was only slightly higher in cases than in controls (3.5 vs 3.0). During the follow-up of patients in the HF cohort overall, all cases and most non-cases (86.3\%) had at least one SBP value recorded between the first HF diagnosis date and the stop date. The mean number of BP records per patient was 11.8 for non-cases and 12.9 for cases.

Due to the nature of data collection during routine clinical practice, we were unable to identify reliably the 
subgroup of cases with orthostatic hypotension. Data on HF severity were not complete for all patients. Therefore, we were only able to adjust for severity indirectly using healthcare utilisation as a proxy measure for overall comorbidity. Data on ejection fraction were also not systematically recorded, preventing us from differentiating between HFrEF and HF with preserved ejection fraction. It is unclear if diagnoses of HF were made according to guidelines, ${ }^{37} 38$ because diagnostic test results are not systematically recorded in the database.

\section{CONCLUSIONS}

In a real-world cohort of 18677 patients newly diagnosed with $\mathrm{HF}$ in the UK, the incidence of hypotension was 3.17 cases per 100 patient-years, and the risk was higher in men than in women. Patients with greater healthcare utilisation (a proxy measure for HF severity and general comorbidity) were at increased risk of developing hypotension, as were those with specific comorbidities including renal failure, ischaemic heart disease, hyperlipidaemia and anaemia, patients with hypotension antecedents and those taking certain medications including aldosterone antagonists, ACE inhibitors and ARBs. As our study is a population-based study in UK primary care with few exclusion criteria, our results should be generalisable to the broader UK population of patients with incident HF. The risk factors identified in this study may help to identify patients most likely to benefit from close BP monitoring. The markedly increased risk of hypotension (as well as ischaemic cerebrovascular events in a previous

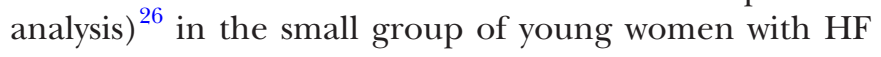
deserves further evaluation.

Acknowledgements Editorial assistance was provided by Dr Claire Mulligan and Dr Paul Overton (Beacon Medical Communications Ltd, Brighton, UK), funded by Bayer AG (Berlin, Germany). This study was presented as a poster at the 34th International Conference on Pharmacoepidemiology \& Therapeutic Risk Management, 22-26 August 2018, Prague, Czech Republic; the corresponding abstract was published in Pharmacoepidemiol Drug Saf 2018;27(Suppl. 2):83-84.

Contributors Conception and design of the research: all authors. Acquisition of data: MM-P, LAGR. Analysis and interpretation of data: MM-P, AM, LAGR. Statistical analysis: MM-P. Obtaining funding and supervising the work: AM, LAGR. Drafting the manuscript: MM, MM-P, AM. Critical revision of the manuscript: all authors. All authors have read and approved the final manuscript.

Funding This work was supported by Bayer AG.

Competing interests MM-P and LAGR work for CEIFE, which has received a research grant from Bayer Pharma AG, Germany. LAGR has also served as an advisory board member for Bayer Pharma AG, Germany. AM is a salaried, full-time employee of Bayer Basel, Switzerland. MM is a salaried, full-time employee of Bayer US LLC., USA.

Patient consent for publication Not required. This study involved the use of anonymised patient medical records, which contained no information that could reasonably be used to identify people.

Ethics approval Data collection for THIN was approved by the South East Multicentre Research Ethics Committee (MREC) in 2003. The study protocol was approved by an independent Scientific Review Committee (reference number 16THIN086).

Provenance and peer review Not commissioned; externally peer reviewed.
Data sharing statement This analysis is based on a large sample from The Health Improvement Network, provided by IMS Health. The authors' licence for using these data precludes the sharing of raw data with third parties.

Open access This is an open access article distributed in accordance with the Creative Commons Attribution Non Commercial (CC BY-NC 4.0) license, which permits others to distribute, remix, adapt, build upon this work non-commercially, and license their derivative works on different terms, provided the original work is properly cited, appropriate credit is given, any changes made indicated, and the use is non-commercial. See: http://creativecommons.org/licenses/by-nc/4.0/.

\section{REFERENCES}

1. Vaduganathan M, Butler J, Pitt B, et al. Contemporary drug development in heart failure: call for hemodynamically neutral therapies. Circ Heart Fail 2015;8:826-31.

2. Davies IB. Chronic hypotension. J R Soc Med 1982;75:577-80.

3. Akosah KO, McHugh VL, Mathiason MA, et al. Closing the heart failure management gap in the community: managing hypotension and impact on outcomes. J Card Fail 2009;15:906-11.

4. Ather S, Chan W, Chillar A, et al. Association of systolic blood pressure with mortality in patients with heart failure with reduced ejection fraction: a complex relationship. Am Heart $J$ 2011;161:567-73.

5. Gheorghiade M, Abraham WT, Albert NM, et al. Systolic blood pressure at admission, clinical characteristics, and outcomes in patients hospitalized with acute heart failure. JAMA 2006;296:2217-26.

6. Mayo Foundation for Medical Education and Research. Low blood pressure (hypotension) - symptoms and causes. 2017 https://www. mayoclinic.org/diseases-conditions/low-blood-pressure/symptomscauses/syc-20355465 (Accessed 18 Feb 2018).

7. Briggs R, Kenny RA, Kennelly SP. Systematic review: the association between late life depression and hypotension. J Am Med Dir Assoc 2016;17:1076-88.

8. Blak BT, Thompson M, Dattani H, et al. Generalisability of The Health Improvement Network (THIN) database: demographics, chronic disease prevalence and mortality rates. Inform Prim Care 2011;19:251-5.

9. Bourke A, Dattani H, Robinson M. Feasibility study and methodology to create a quality-evaluated database of primary care data. Inform Prim Care 2004:12:171-7.

10. Stuart-Buttle CD, Read JD, Sanderson HF, et al. A language of health in action: read codes, classifications and groupings. Proc AMIA Annu Fall Symp 1996:75-9.

11. In Practice Systems Ltd. Gemscript Â the new DM+D drug dictionary for Vision. http://www.inps4.co.uk/my-vision/news/gemscript-\%C3\% $82 \% \mathrm{C} 2 \% 96-n e w-d m d$-drug-dictionary-vision (Accessed 18 Feb 2018).

12. Lewis JD, Schinnar R, Bilker WB, et al. Validation studies of the health improvement network (THIN) database for pharmacoepidemiology research. Pharmacoepidemiol Drug Saf 2007;16:393-401.

13. Ruigomez A, Garcia Rodriguez LA, Michel A. Incidence of heart failure: a population-based study in a general practice setting. Pharmacoepidemiol Drug Saf 2014;23(Suppl. 1):453-4.

14. Valente MA, Hillege HL, Navis G, et al. The chronic kidney disease epidemiology collaboration equation outperforms the modification of diet in renal disease equation for estimating glomerular filtration rate in chronic systolic heart failure. Eur J Heart Fail 2014;16:86-94.

15. lyngkaran $\mathrm{P}$, Thomas $\mathrm{M}$, Majoni W, et al. Comorbid heart failure and renal impairment: epidemiology and management. Cardiorenal Med 2012;2:281-97.

16. Rouleau JL, Roecker EB, Tendera M, et al. Influence of pretreatment systolic blood pressure on the effect of carvedilol in patients with severe chronic heart failure: the Carvedilol Prospective Randomized Cumulative Survival (COPERNICUS) study. J Am Coll Cardiol 2004;43:1423-9.

17. Serov VA, Shutov AM, Serova DV, et al. [Prognostic value of detection of arterial hypotensive episodes in patients with chronic heart failure]. Ter Arkh 2014;86:8-12.

18. Bozkurt B, Agoston I, Knowlton AA. Complications of inappropriate use of spironolactone in heart failure: when an old medicine spirals out of new guidelines. J Am Coll Cardiol 2003;41:211-4.

19. Gheorghiade $\mathrm{M}$, Vaduganathan $\mathrm{M}$, Ambrosy $\mathrm{A}$, et al. Current management and future directions for the treatment of patients hospitalized for heart failure with low blood pressure. Heart Fail Rev 2013;18:107-22. 
20. Esteras R, Perez-Gomez MV, Rodriguez-Osorio L, et al. Combination use of medicines from two classes of renin-angiotensin system blocking agents: risk of hyperkalemia, hypotension, and impaired renal function. Ther Adv Drug Saf 2015;6:166-76.

21. CONSENSUS Trial Study Group. Effects of enalapril on mortality in severe congestive heart failure. Results of the Cooperative North Scandinavian Enalapril Survival Study (CONSENSUS). N Engl J Med 1987;316:1429-35.

22. Yusuf S, Pitt B, Davis CE, et al. Effect of enalapril on survival in patients with reduced left ventricular ejection fractions and congestive heart failure. N Engl J Med 1991;325:293-302.

23. McMurray J, Cohen-Solal A, Dietz R, et al. Practical recommendations for the use of ACE inhibitors, beta-blockers, aldosterone antagonists and angiotensin receptor blockers in heart failure: putting guidelines into practice. Eur $J$ Heart Fail 2005;7:710-21.

24. Bangalore S, Kumar S, Messerli FH. When conventional heart failure therapy is not enough: angiotensin receptor blocker, direct renin inhibitor, or aldosterone antagonist? Congest Heart Fail 2013;19:107-15.

25. Bozkurt B. Response to Ryan and Parwani: heart failure patients with low blood pressure: how should we manage neurohormonal blocking drugs? Circ Heart Fail 2012;5:820-1.

26. Michel A, Martin-Perez M, Ruigomez A, et al. P3238 Risk of first ischemic cerebrovascular event in a cohort of incident heart failure patients. Eur Heart J 2017;38(Suppl. 1):656-7.

27. Ricci F, Fedorowski A, Radico F, et al. Cardiovascular morbidity and mortality related to orthostatic hypotension: a meta-analysis of prospective observational studies. Eur Heart J 2015;36:1609-17.

28. Meredith PA, Ostergren J, Anand I, et al. Clinical outcomes according to baseline blood pressure in patients with a low ejection fraction in the CHARM (Candesartan in heart failure: assessment of reduction in mortality and morbidity) program. J Am Coll Cardiol 2008;52:2000-7.
29. Petrie JR, Guzik TJ, Touyz RM. Diabetes, hypertension, and cardiovascular disease: clinical insights and vascular mechanisms. Can J Cardiol 2018;34:575-84.

30. DeMarco VG, Aroor AR, Sowers JR. The pathophysiology of hypertension in patients with obesity. Nat Rev Endocrinol 2014;10:364-76.

31. Owens PE, Lyons SP, O'Brien ET. Arterial hypotension: prevalence of low blood pressure in the general population using ambulatory blood pressure monitoring. J Hum Hypertens 2000;14:243-7.

32. O'Callaghan S, Kenny RA. Neurocardiovascular instability and cognition. Yale J Biol Med 2016;89:59-71.

33. Sveinbjornsdottir S. The clinical symptoms of Parkinson's disease. $J$ Neurochem 2016;139(Suppl. 1):318-24.

34. Rutledge T, Reis VA, Linke SE, et al. Depression in heart failure a meta-analytic review of prevalence, intervention effects, and associations with clinical outcomes. J Am Coll Cardiol 2006;48:1527-37.

35. Mozaffarian D, Nye R, Levy WC. Anemia predicts mortality in severe heart failure: the prospective randomized amlodipine survival evaluation (PRAISE). J Am Coll Cardiol 2003;41:1933-9.

36. Horwich TB, Fonarow GC, Hamilton MA, et al. Anemia is associated with worse symptoms, greater impairment in functional capacity and a significant increase in mortality in patients with advanced heart failure. J Am Coll Cardiol 2002;39:1780-6.

37. Ponikowski P, Voors AA, Anker SD, et al. ESC Scientific Document Group. 2016 ESC Guidelines for the diagnosis and treatment of acute and chronic heart failure: The Task Force for the diagnosis and treatment of acute and chronic heart failure of the European Society of Cardiology (ESC)Developed with the special contribution of the Heart Failure Association (HFA) of the ESC. Eur Heart $J$ 2016;37:2129-200.

38. Remme WJ, Swedberg K. Task Force for the Diagnosis and Treatment of Chronic Heart Failure, European Society of Cardiology. Guidelines for the diagnosis and treatment of chronic heart failure. Eur Heart J 2001;22:1527-60. 